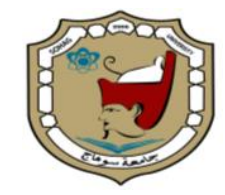

Sohag University

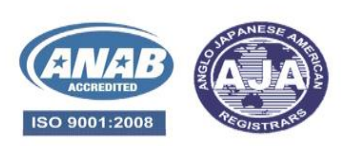

Sohag Medical Journal
Faculty of Medicine

\title{
Chest wall reconstruction with a methyl-methacrylate sandwich after resection of large chest wall tumors: single center experience
}

\author{
Essam Elbadry Hashim Mohamed ${ }^{1}$, Abdelhady Ahmed Helmy ${ }^{2}$ \\ 1-Cardiothoracic surgery department, faculty of medicine, Sohag University, Sohag, Egypt \\ 2- Anesthesia and intensive care department, faculty of medicine, Sohag University, Sohag, \\ Egypt
}

\begin{abstract}
:
Background: The advantages of methyl-methacrylate sandwich for chest wall reconstruction are controversial. We aimed to report the outcomes of chest wall reconstruction using a methylmethacrylate sandwich after large tumor resection.

Methods: This retrospective research included 30 patients who had chest wall reconstruction after resection of large tumors from January 2010 to December 2018 at a single center. All patients had skeletal reconstruction using a methyl-methacrylate sandwich with a Prolene mesh. Soft-tissue construction was performed with primary closure $(n=12)$, latissimus dorsi flap $(n=10)$, local flap $(n=4)$, and pectoralis muscle flap $(n=4)$.

Results: Male presented $73.3 \%$ of the patients $(n=22)$ and the median age was 50 years (range: 20 - 75). The pathology of the resected tumors were infiltrating carcinoma of the lung $(n=6 ; 20 \%)$, undifferentiated pleomorphic sarcoma $(n=4 ; 13.3 \%)$, chondrosarcoma $(n=4 ; 13.3 \%)$, infiltrating adenocarcinoma of mesothelial origin $(n=4 ; 13.3 \%)$, adenocarcinoma of lung origin $(n=2 ; 6.7 \%)$, osteochondroma $(n=2 ; 6.7 \%)$, Ewing sarcoma $(n=2 ; 6.7 \%)$, round cell sarcoma $(n=2 ; 6.7 \%)$, sternal sarcoma $(n=2 ; 6.7 \%)$, and chondroma $(n=2 ; 6.7 \%)$. Postoperative complications occurred in 14 patients; atelectasis $(\mathrm{n}=4 ; 13.3 \%)$ consolidation $(\mathrm{n}=2 ; 6.7 \%)$, wound infection $(\mathrm{n}=2$; $6.7 \%)$, flap seroma $(n=2 ; 6.7 \%)$, acute respiratory distress syndrome $(n=2 ; 6.7 \%)$ and local recurrence $(n=2 ; 6.7 \%)$. We reported two late mortalities because of distant metastasis and sepsis Conclusion: Immediate reconstruction of large chest wall defects following tumor resection could be feasible using methyl-methacrylate filler with synthetic mesh with accepted morbidity and mortality.
\end{abstract}

Keywords: methyl-methacrylate; chest wall reconstruction; chest wall tumors

\section{Background:}

Chest wall resection is commonly performed for malignant tumors (1). Chest wall reconstruction provides better cosmesis, improves the ventilatory function, and prevents lung herniation and scapular impaction (2).

Chest wall reconstruction after resection of large tumors remains technically challenging.
Several materials are available to construct larger defects, including bone grafts, prosthetic materials, and synthetic mesh (3). These materials either lack sufficient strength or flexibility to perform efficient reconstruction of large defects. Methylmethacrylate was introduced to the armamentarium of chest wall reconstruction, 
which can provide rigidity and conforms to the chest wall defects (4).

However, the use of methyl-methacrylate may be associated with an increased risk of infection and seroma formation; additionally, the rigidity may impair respiratory mechanics. The study's objective was to report chest wall reconstruction outcomes using a methyl-methacrylate sandwich after the resection of large tumors. Additionally, we compared our results to the published series

\section{Methods:}

\section{Design}

This retrospective research included 30 patients who had chest wall reconstruction after resection of chest wall tumors from January 2010 to December 2018 at a single center. We included patients who had resection of three or more ribs and/or sternum for primary chest wall tumors or tumors infiltrating the chest wall from the surrounding structures. We did not include patients who had resection of fewer than three ribs or for defects under the scapula. All patients had skeletal reconstruction using a methyl-methacrylate sandwich with Prolene mesh (Ethicon, Somerville, NJ, USA). We used Prolene meshes in all patients because they are resistant to infection, degradation, easy to handle, and supplied in different sizes. Moreover, they promote tissue ingrowth and will eventually be integrated into the human body.

The Local Ethical Committee approved the study with a waiver of patients' consent.

Data and techniques

Data collected for the study included age, gender, the pathological type of the tumor, the number of ribs resected, and the method of skeletal and soft tissue reconstruction. All patients had preoperative pulmonary function tests, chest computed tomography (CT) scans, and metastatic workup. The preoperative CT scan showed the extent of the tumor, the number of ribs involved, and the involvement of intra-thoracic structures. (Figure 1)

A multidisciplinary team, including surgeons, oncologists, and anesthesiologists, shared in patients' management. Doublelumen endotracheal was used inserted in all patients. We entered the thoracic cavity through healthy intercostal spaces above and below the tumors. We performed en-bloc resection of the tumors together with the involved mediastinal structures (i.e., the pericardium was resected in one patient), lung or pleura (Figure 2), and normal skin margins and ribs above and below. (Figure 3 A, B) A frozen section was performed in all patients to determine tumor-free margins. The methyl-methacrylate was prepared by mixing 40 grams of the powder with $20 \mathrm{ml}$ of provided solvent. The methyl-methacrylate paste was distributed between the two layers of the Prolene mesh as a single layer. We left $1-2 \mathrm{~cm}$ from all edges free from the methylmethacrylate paste to be fixed to the ribs above and below the defect using nonabsorbable sutures. We folded the Prolene mesh to form a second layer on the methylmethacrylate paste (figure $3 \mathrm{C}$ ). In the patient with a sternal tumor, the sternum was resected using the oscillating saw, and reconstruction was performed in a similar way as another chest tumor. Skeletal reconstruction was the same for all patients, and soft tissue reconstruction with direct closure of flaps was performed according to the size of the defect, surgeon expertise, and the proximity to the defect.

We routinely used thoracic epidural catheter for postoperative pain management. Patients were managed postoperatively with aggressive physiotherapy and pain management to prevent pulmonary complications. Patients had postoperative CT chest to assess the repair and detect complications. (Figure 4). We reported postoperative complications, tumor recurrence, and early and late mortality. 

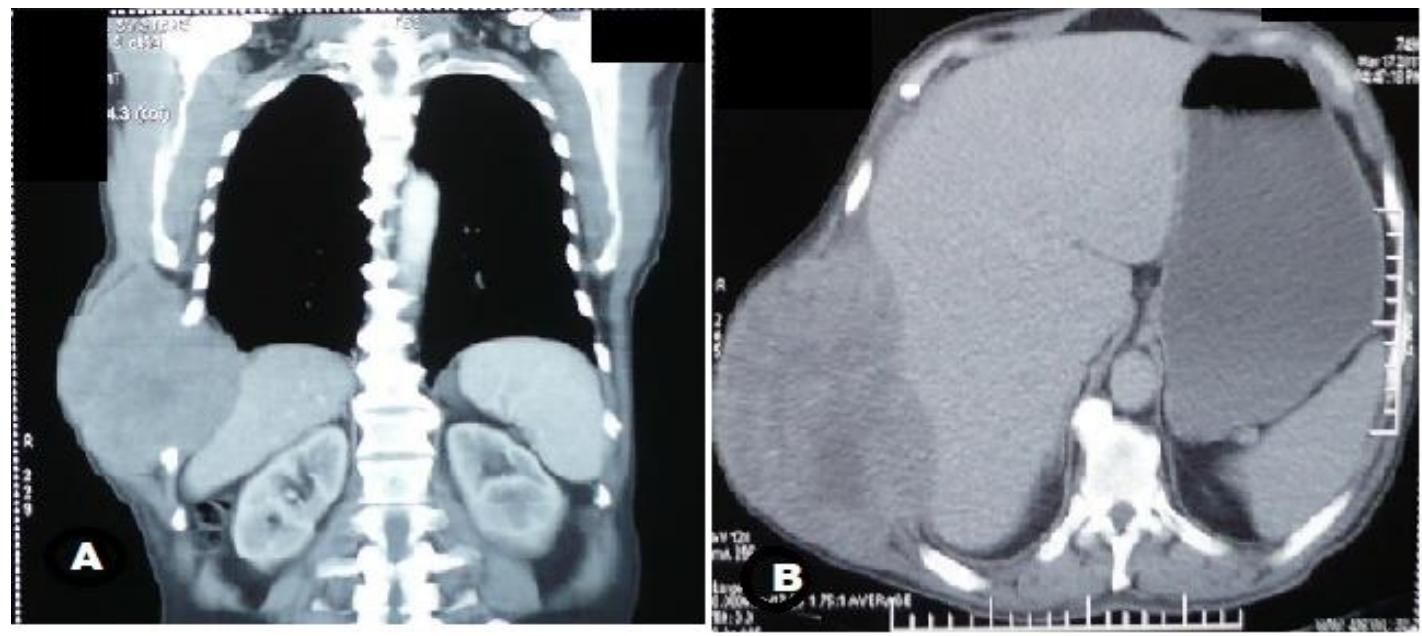

Figure 1: Preoperative CT chest; coronal (A) and axial (B) views showing right-side chest wall tumor.

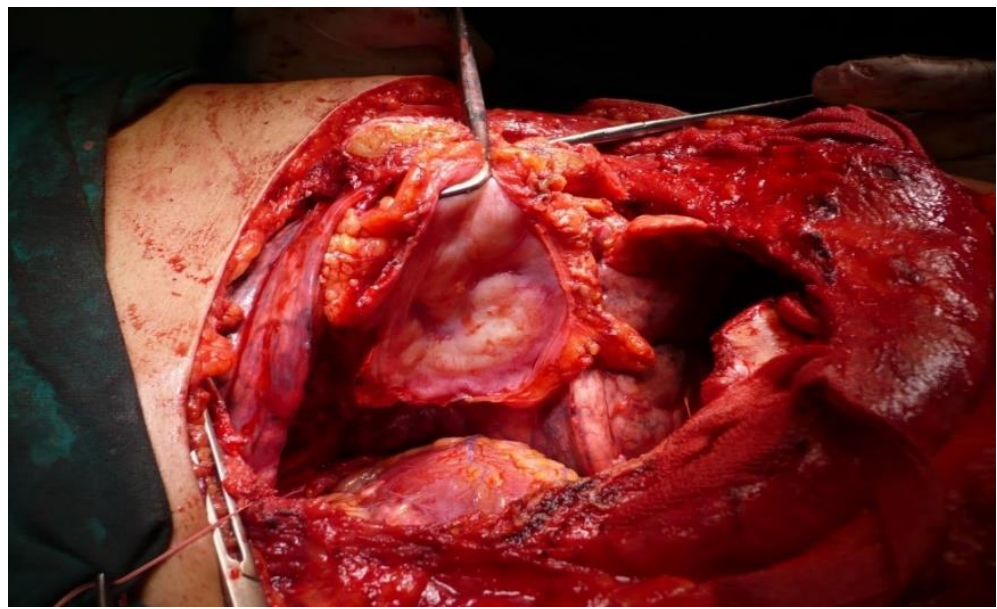

Figure 2: En-bloc resection of chest wall tumor with three ribs, wedge resection of the left lower lung lobe and lateral part of the pericardium
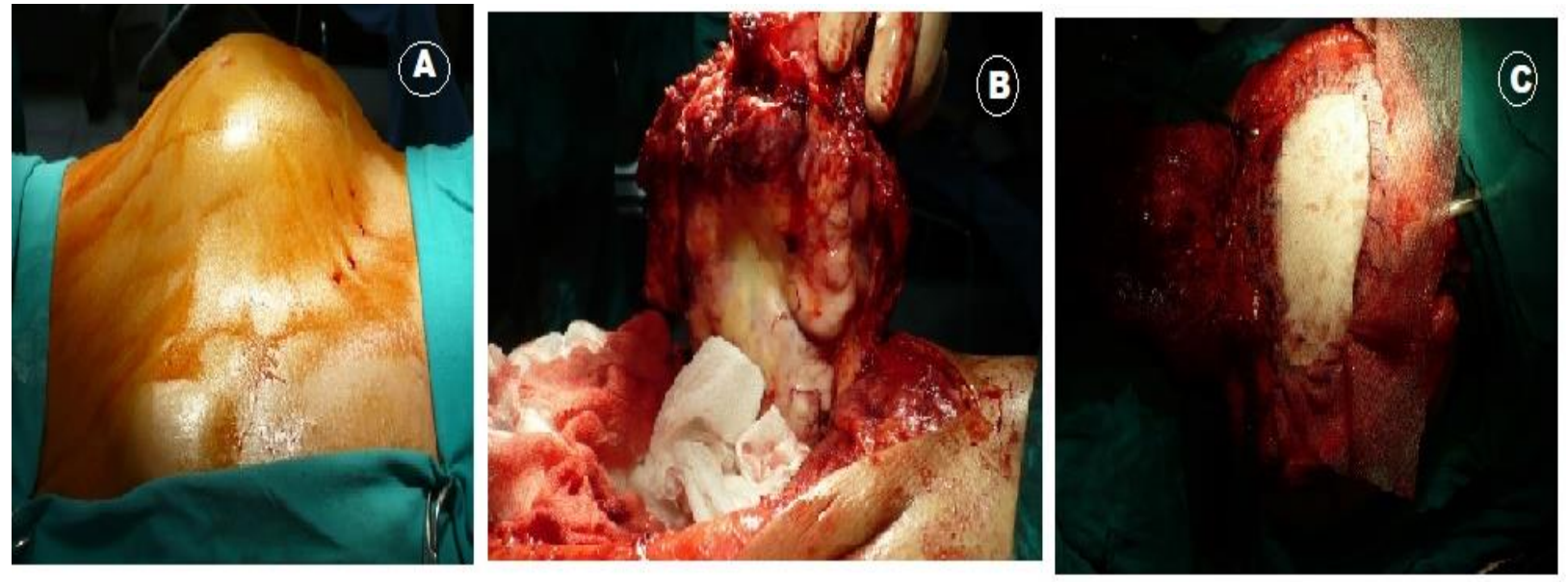

Figure 3: Operative resection of large chest wall tumor A) operative view, B) en-bloc resection of the tumor with the $7^{\text {th }}, 8^{\text {th }}$ and $9^{\text {th }}$ ribs, C) chest wall reconstruction using a methyl-methacrylate-Prolene sandwich. 


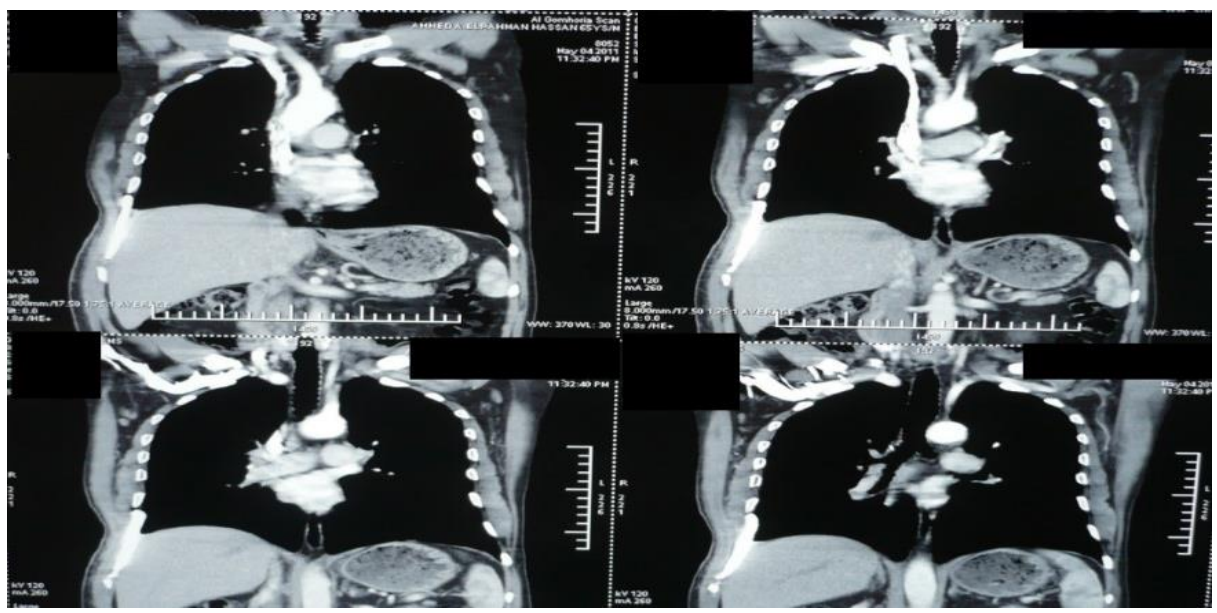

Figure 4: Postoperative CT scan after chest wall reconstruction

\section{Statistical analysis}

A descriptive analysis was used to present our data. We presented the continuous data as median and range and binary data as number and percentage.

\section{Results:}

Male presented $73.3 \%$ of the patients $(n=22)$, and the median age was 50 years (range: 20 75). The most common resected tumors were infiltrating squamous cell carcinoma of the lung $(n=6 ; 20 \%)$, undifferentiated pleomorphic sarcoma $(\mathrm{n}=4 ; 13.3 \%)$, chondrosarcoma $(\mathrm{n}=4,13.3 \%)$, and infiltrating adenocarcinoma of mesothelial origin $(n=4 ; 13.3 \%)$ (Table 1).

We resected three ribs in 24 patients $(80 \%)$, four ribs in 4 patients $(13.3 \%)$, and the sternu$\mathrm{m}$ in 2 patients $(6.7 \%)$. Associated pleuropulmonary resection was performed in 12 patients $(40 \%)$. The defect was inferior- lateral in 7 cases, superior -lateral in 5, anterior in 11, And posterior in 7 cases. We performed skeletal reconstruction with methyl-methacrylate sandwich with a Prolene mesh in all patients, and soft-tissue construction was performed with primary closure $(n=12$, $40 \%)$, latissimus dorsi flap $(n=10 ; 33.3 \%)$, local flap $(n=4 ; 13.3)$, and pectoralis muscle flap $(n=4 ; 13.3 \%)$. Postoperative complications occurred in 14 patients (46.7\%). (Table 2) six patients who had associated pleuropulmonary procedures developed postoperative complications. (Table 3) two patients had local recurrence, and we revised the surgery with excision of the local recurrence with a wider safety margin. Then, we performed chest wall reconstruction with the same technique.

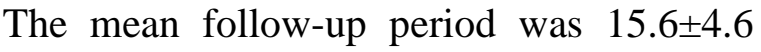
months (range: 9 - 42 months). We reported two late mortalities because of distant metastasis $(\mathrm{n}=1 ; 3.35 \%)$ and sepsis $(\mathrm{n}=1 ; 3.35 \%)$. One patient had chondrosarcoma involving three ribs with no affection of the intra-thoracic structures, and the second patient had Ewing sarcoma involving four ribs.

\begin{tabular}{|l|l|}
\hline Pathological type of the tumor & $(\mathrm{n}=30)$ \\
\hline Infiltrating squamous cell carcinoma of & $6(20 \%)$ \\
\hline Undifferentiated pleomorphic sarcoma & $4(13.3 \%)$ \\
\hline Chondrosarcoma & $4(13.3 \%)$ \\
\hline $\begin{array}{l}\text { Infiltrating adenocarcinoma of mesot- } \\
\text { helial origin }\end{array}$ & $4(13.3 \%)$ \\
\hline Adenocarcinoma of lung origin & $2(6.7 \%)$ \\
\hline Osteosarcoma & $2(6.7 \%)$ \\
\hline Ewing sarcoma & $2(6.7 \%)$ \\
\hline Round cell sarcoma & $2(6.7 \%)$ \\
\hline Sternal sarcoma & $2(6.7 \%)$ \\
\hline Chondroma & $2(6.7 \%)$ \\
\hline
\end{tabular}

Table 1: Pathological types of resected tumors 
SOHAG MEDICAL JOURNAL Vol. 25 No. 1 Jan 2021

\begin{tabular}{|c|c|}
\hline Postoperative complications & \\
\hline Atelectasis & $4(13.3 \%)$ \\
\hline Wound infection & $2(6.7 \%)$ \\
\hline Flap seroma & $2(6.7 \%)$ \\
\hline Acute respiratory distress syndrome & $2(6.7 \%)$ \\
\hline Local recurrence & $2(6.7 \%)$ \\
\hline Consolidation & $2(6.7 \%)$ \\
\hline
\end{tabular}

Table 2: Postoperative complications
Chest wall reconstruction with a methyl-methacrylate sandwich after resection Essam Elbadry Hashim Mohamed

\begin{tabular}{|l|l|}
\hline $\begin{array}{l}\text { Pleural and pulmonary } \\
\text { procedure }(\mathrm{n}=12)\end{array}$ & Complications \\
\hline Lobectomy $(\mathrm{n}=4)$ & $\begin{array}{l}\text { Wound } \\
\text { infection/ } \\
\text { atelectasis }\end{array}$ \\
\hline $\begin{array}{l}\text { Non anatomical resection }(\mathrm{n}= \\
4)\end{array}$ & $\begin{array}{l}\text { Consolidation/ } \\
\text { no complications }\end{array}$ \\
\hline Pleurectomy $(\mathrm{n}=4)$ & $\begin{array}{l}\text { No } \\
\text { complications }\end{array}$ \\
\hline
\end{tabular}

Table 3: The concomitant pleuropulmonary procedures and the associated complications:

\begin{tabular}{|l|l|l|}
\hline Studies & Number of patients & Complications \\
\hline Kilic et al. (13) & 38 patients & $\begin{array}{l}\text { Infection }(\mathrm{n}=1) \\
\text { Respiratory failure }(\mathrm{n}=1)\end{array}$ \\
\hline Chapelier et al. (14) & 7 patients & $\begin{array}{l}\text { Infection }(\mathrm{n}=2) \\
\text { Respiratory failure }(\mathrm{n}=1)\end{array}$ \\
\hline Khalil et al. (15) & 29 patients & Infection $(\mathrm{n}=2)$ \\
\hline Rocco et al. (17) & 15 patients & No complications \\
\hline Aghajanzadeh et al. (18) & 20 patients & $\begin{array}{l}\text { Infection }(\mathrm{n}=1) \\
\text { Respiratory failure }(\mathrm{n}=2) \\
\text { Atelectasis }(\mathrm{n}=4) \\
\text { Pneumonia }(\mathrm{n}=2)\end{array}$ \\
\hline Weyant et al. (19) & 112 patients & $\begin{array}{l}\text { Respiratory failure }(\mathrm{n}=3) \\
\text { Atelectasis }(\mathrm{n}=3) \\
\text { Pneumonia }(\mathrm{n}=2)\end{array}$ \\
\hline Foroulis et al. (20) & 9 patients & $\begin{array}{l}\text { Atelectasis }(\mathrm{n}=2) \\
\text { Dislodgement }(\mathrm{n}=1)\end{array}$ \\
\hline Parker et al. (21) & 1 patient & Dislodgement $(\mathrm{n}=1)$ \\
\hline Fouad et al. (22) & 11 patients & $\begin{array}{l}\text { Infection }(\mathrm{n}=1) \\
\text { Pneumonia }(\mathrm{n}=1) \\
\end{array}$ \\
& & $\begin{array}{l}\text { Collapse }(\mathrm{n}=1) \\
\text { Acute respiratory distress syndrome }(\mathrm{n}=1)\end{array}$ \\
\hline
\end{tabular}

Table 4:

Outcomes of chest wall reconstruction using methylmethacrylate sandwich:

\section{Discussion:}

The basic surgical principles for managing chest wall tumors include resection of all pathological tissue with suitable safety margins, reconstructing the chest wall with a rigid material followed by soft tissue coverage (5). Chest wall reconstruction aims to restore normal chest wall mechanics and eliminate the paradoxical chest wall motion. Small defects involving the resection of fewer than three ribs could be repaired with soft tissue coverage; however, larger defects usually need a rigid material for better chest wall stability.
Several materials are available for reconstruction, but most of them lack the flexibility to conform with the complex chest wall anatomy. Soft tissue coverage of large chest wall defects is associated with prolonged mechanical ventilation and paradoxical chest wall motion. Researchers found that rigid materials used for chest wall reconstruction improved postoperative blood gases and pulmonary functions $(6,7)$. The reconstructing material should be resistant to infection, degradation, easy to handle, and supplied in different sizes. Moreover, they promote tissue ingrowth 
and will eventually be integrated into the human body. (6) Methyl-methacrylate was used for the reconstruction of chest wall defects to provide rigidity and flexibility (8). The methyl-methacrylate repair can be combined with several materials, and the most common are Prolene or Marlex mesh $(9,10)$. Marlex is a single-knit mesh, while Prolene is a doubleknitted mesh (11). Both types of meshes have fenestrations that allow vascular infiltration (12). In our study, we used the Prolene sandwich in all patients. It was found that chest wall reconstruction with methyl-methacrylate was associated with improved respiretory functions and concordant chest wall movement after a 6-month follow-up (4). The Methyl-methacrylate sandwich is the most commonly reported technique in the literature (9). The most common complication reported with the sandwich technique was infection (13-15), and the infection rate was lower with the non-sandwich approach (9). Earlier studies showed that the prosthetic materials did not increase the risk of infection or foreign body reaction after chest wall reconstruction (16). In this study, we reported two patients with postoperative wound infection $(6.67 \%)$, both had a resection for invasive pulmonary squamous cell carcinoma and soft tissue construction with pectoralis flap. Management of infection is usually conservative and does not require prosthesis removal. None of our patients required removal of the prosthesis, Rocco and co-investigators evaluated reinterventions and the need for prosthesis removal after chest wall reconstruction. They did not report reintervention and removal of the prosthesis in patients who had reconstruction using methyl-methacrylate material (17).

We reported atelectasis in four patients $(13.33 \%)$. Patients undergoing chest wall reconstruction are highly vulnerable to develop postoperative atelectasis, which can be prevented with aggressive physiotherapy. A higher rate of atelectasis was reported in other stud- ies. Aghajanzadeh and associates in a study including 162 patients with chest wall reconstruction, 20 patients had reconstruction with a methyl-methacrylate sandwich; 4 of them had postoperative atelectasis (18). In a larger series of 262 patients by Weyant and associates, 112 patients had reconstruction using the methyl-methacrylate sandwich technique. They reported atelectasis in 3 patients $(2.7 \%)$, pneumonia in $2(1.8 \%)$ and respiratory failure in 3 patients $(2.7 \%)$ (19).

Respiratory failure is a severe complication after chest wall tumor resection. We reported two patients developed postoperative acute respiratory distress syndrome. Postoperative respiratory failure rates varied widely in the literature and ranged from $0-20 \%(13,18,19)$. This wide variability in respiratory failure rate could be due to several factors, including different patients' specific risk factors, type of tumor, the extent of resection, associated pulmonary resections, and the center's volume. Rare complications were reported with chest wall reconstruction using methyl-methacrylate, such as prosthesis dislodgement. Foroulis and associates reported one case of prosthesis dislodgement out of nine patients who had massive chest wall reconstruction for malignant tumors (20). Parker and coworkers reported a case of methyl-methacrylate prosthesis migration that led to the development of aortic pseudoaneurysm and aortopulmonary fistula (21). In our series, we did not report any case of prothesis migration.

We did not report postoperative mortality in our series, but two late mortalities occurred because of sepsis and distant metastasis. Several other series reported no operative mortality with the use of methyl-methacrylate chest wall reconstruction (22). In a literature review, mortality occurred in $1.7 \%$ with the methyl-methacrylate sandwich and $2.7 \%$ in the non-sandwich technique (9). (Table 4)

Several modifications of the methyl-methacrylate technique have been described. Shah 
and colleagues described the use of a biologyical mesh with methyl-methacrylate (9). Suzuki and associates described the use of methyl-methacrylate neo-rib in addition to Prolene mesh (23). These techniques were described in case reports, and their advantages over the standard technique cannot be evaluated.

Few studies have compared methyl-methacrylate with other synthetic grafts. Kilic and colleagues compared Mersilene mesh methyl-methacrylate sandwich and polytetrafluoroethylene grafts. They reported a lower rate of paradoxical motion with methyl-methacrylate and shorter hospital stay (13).

Methyl-methacrylate can be used for other chest wall reconstruction indications, such as stabilizing the flail chest (24). Recently, several synthetic materials have been introduced for chest wall reconstruction (25), and 3D printing was used to tailor chest wall reconstruction to the patient's specific anatomy (26).

\section{Study limitations}

The study is retrospective with a small number of patients. However, this study design is suitable for studying rare diseases and procedures. Moreover, the number of our patients is comparable to what was published in the literature. Additionally, we reported our experience using methyl-methacrylate, and we did not compare the outcomes to other techniques. This is because methyl-methacrylate is the most common material we use for chest wall reconstruction in our center.

\section{Conclusion:}

Immediate reconstruction of large chest wall defects following tumor resection could be feasible using methyl-methacrylate filler wit$\mathrm{h}$ synthetic mesh with accepted morbidity and mortality.

Abbreviations: not applicable

\section{References:}

1. Mansour KA, Thourani VH, Locken A, Reeves JG, Miller JIJ, Carlson GW, et al.
Chest wall resections and reconstruction: a 25year experience. Ann Thorac Surg. 2002 Jun;73(6):1720-6.

2. Salo JTK, Tukiainen EJ. Oncologic Resection and Reconstruction of the Chest Wall: A 19Year Experience in a Single Center. Plast Reconstr Surg. 2018 Aug;142(2):536-47.

3. Thomas PA, Brouchet L. Prosthetic reconstruction of the chest wall. Thorac Surg Clin. 2010 Nov;20(4):551-8.

4. Lardinois D, Müller M, Furrer M, Banic A, Gugger M, Krueger $\mathrm{T}$, et al. Functional assessment of chest wall integrity after methylmethacrylate reconstruction. Ann Thorac Surg. 2000 Mar;69(3):919-23.

5. Arnold PG, Pairolero PC. Chest-wall reconstruction: an account of 500 consecutive patients. Plast Reconstr Surg. 1996 Oct;98(5):804-10.

6. Kroll SS, Walsh G, Ryan B, King RC. Risks and benefits of using Marlex mesh in chest wall reconstruction. Ann Plast Surg. 1993 Oct;31(4):303-6.

7. Novoa N, Benito P, Jiménez MF, de Juan A, Luis Aranda J, Varela G. Reconstruction of chest wall defects after resection of large neoplasms: ten-year experience. Interact Cardiovasc Thorac Surg. 2005 Jun;4(3):2505.

8. Groth AK, Pazio ALB, Kusano LDC, Lupion F, Itikawa WM, Legnani BC, et al. Thoracic Wall Reconstruction: Surgical Planning in Extended Malignant Resections. Ann Plast Surg. 2020 Nov;85(5):531-8.

9. Shah NR, Ayyala HS, Tran BNN, Therattil PJ, Keith JD. Outcomes in Chest Wall Reconstruction Using Methyl Methacrylate Prostheses: A Review of the Literature and Case Series Utilizing a Novel Approach with Biologic Mesh. J Reconstr Microsurg. 2019 Oct;35(8):575-86.

10. Ng CSH. Recent and Future Developments in Chest Wall Reconstruction. Semin Thorac Cardiovasc Surg. 2015;27(2):234-9.

11. McCormack PM. Use of prosthetic materials in chest-wall reconstruction. Assets and liabilities. Surg Clin North Am. 1989 Oct;69(5):965-76.

12. Mahabir RC, Butler CE. Stabilization of the chest wall: autologous and alloplastic 
reconstructions. Semin Plast Surg. 2011 Feb;25(1):34-42.

13. Kilic D, Gungor A, Kavukcu S, Okten I, Ozdemir N, Akal M, et al. Comparison of mersilene mesh-methyl metacrylate sandwich and polytetrafluoroethylene grafts for chest wall reconstruction. J Investig Surg Off $\mathbf{J}$ Acad Surg Res. 2006;19(6):353-60.

14. Chapelier AR, Missana M-C, Couturaud B, Fadel E, Fabre D, Mussot S, et al. Sternal resection and reconstruction for primary malignant tumors. Ann Thorac Surg. 2004 Mar;77(3):1001-7.

15. Khalil HH, Malahias MN, Balasubramanian B, Djearaman MG, Naidu B, Grainger MF, et al. Multidisciplinary Oncoplastic Approach Reduces Infection in Chest Wall Resection and Reconstruction for Malignant Chest Wall Tumors. Plast Reconstr surgery Glob open. 2016 Jul;4(7):e809.

16. Incarbone M, Pastorino U. Surgical treatment of chest wall tumors. World J Surg. 2001 Feb;25(2):218-30.

17. Rocco G, Martucci N, La Rocca A, La Manna C, De Luca G, Fazioli F, et al. Postoperative local morbidity and the use of vacuumassisted closure after complex chest wall reconstructions with new and conventional materials. Ann Thorac Surg. 2014 Jul;98(1):291-6.

18. Aghajanzadeh M, Alavy A, Taskindost M, Pourrasouly Z, Aghajanzadeh G, Massahnia S. Results of chest wall resection and reconstruction in 162 patients with benign and malignant chest wall disease. J Thorac Dis. 2010 Jun;2(2):81-5.

19. Weyant MJ, Bains MS, Venkatraman E, Downey RJ, Park BJ, Flores RM, et al. Results of chest wall resection and reconstruction with and without rigid prosthesis. Ann Thorac Surg. 2006 Jan;81(1):279-85.

20. Foroulis CN, Kleontas AD, Tagarakis G, Nana C, Alexiou I, Grosomanidis V, et al. Massive chest wall resection and reconstruction for malignant disease. Onco Targets Ther. 2016;9:2349-58.

21. Parker KL, Thistlethwaite P, Suliman AS, Reid C, Tenenhaus M, El Khoury Z, et al. Staged Repair of an Aortic Pseudoaneurysm Secondary to Delayed Methylmethacrylate Plate Migration. Ann Thorac Surg. 2017 Feb;103(2):e139-41.

22. Fouad FA. Chest wall resection and reconstruction: analysis of 11 cases after methylmethacrylate reconstruction. J Egypt Natl Canc Inst. 2006 Sep;18(3):175-82.

23. Suzuki K, Park BJ, Adusumilli PS, Rizk NP, Huang J, Jones DR, et al. Chest Wall Reconstruction Using a Methyl Methacrylate Neo-Rib and Mesh. Ann Thorac Surg. 2015 Aug;100(2):744-7.

24. Bibas BJ, Bibas RA. Operative stabilization of flail chest using a prosthetic mesh and methylmethacrylate. Eur $\mathrm{J}$ cardio-thoracic Surg. 2006 Jun;29(6):1064-6.

25. Berthet JP, Canaud L, D'Annoville T, Alric P, Marty-Ane C-H. Titanium plates and Dualmesh: a modern combination for reconstructing very large chest wall defects. Ann Thorac Surg. 2011 Jun;91(6):1709-16.

26. Smelt J, Pontiki A, Jahangiri M, Rhode K, Nair A, Bille A. Three-Dimensional Printing for Chest Wall Reconstruction in Thoracic Surgery: Building on Experience. Thorac Cardiovasc Surg. 2020 Jun;68(4):352-6. 